\title{
A priming technique accelerates onset of neuromus- cular blockade at the laryngeal adductor muscles
}

\section{[Une technique d'amorçage accélère le blocage neuromusculaire au niveau des}

\author{
muscles adducteurs du larynx]
}

Joachim Schmidt MD, ${ }^{*}$ Andrea Irouschek, ${ }^{*}$ Tino Muenster MD, ${ }^{*}$ Thomas M. Hemmerling MD DEAA, $\dagger$ Sven Albrecht MD*

Purpose: Priming is a known technique to accelerate onset of neuromuscular blockade (NMB). Its effect on NMB of the larynx has not been studied yet.

Methods: We compared a priming technique with a bolus application of rocuronium on the onset of NMB at the laryngeal adductor and the adductor pollicis muscles (AP). In 30 female patients, after induction of anesthesia a tube with a surface electrode was placed into the trachea prior to the administration of any neuromuscular blocking agent to monitor electromyography (EMG) of the laryngeal adductor muscles. Neuromuscular monitoring consisted of EMG of the laryngeal adductor muscles and the left AP. Patients were randomized into two groups. After transcutaneous stimulation of the recurrent laryngeal nerve and ulnar nerve, a bolus of rocuronium $0.6 \mathrm{mg} \cdot \mathrm{kg}^{-1}$ (Bolus group) or a priming dose of rocuronium $0.06 \mathrm{mg} \cdot \mathrm{kg}^{-1}$ followed by rocuronium $0.54 \mathrm{mg} \cdot \mathrm{kg}^{-1}$ three minutes later (Priming group) were injected. Lag time, onset $90 \%$, onset time and peak effect of NMB were recorded and compared; a $P<0.05$ was considered significant.

Results: The onset $90 \%$ and onset time measured at the laryngeal adductor muscles (onset: $44.7 \pm 7.4$ vs $74.0 \pm 23.8 \mathrm{sec}$ ) and at the AP (onset: $105.4 \pm 29.9$ vs $139.2 \pm 51.5 \mathrm{sec}$ ) were significantly shorter in the Priming group than in the Bolus group. Within groups, the onset times were significantly shorter at the laryngeal muscles in comparison to AP.

Conclusion: Our results indicate that a priming technique with rocuronium significantly accelerates the onset of NMB at the laryngeal adductor muscles. Our results further support the use of rocuronium as an alternative to succinylcholine for rapid sequence induction.
Objectif : L'amorçage est une technique connue pour accélérer l'installation du blocage neuromusculaire (BNM). Son effet sur le BNM du larynx n'a pas encore été étudié.

Méthode : Nous avons comparé une technique d'amorçage et l'injection de bolus de rocuronium au début du BNM de l'adducteur du larynx et de l'adducteur du pouce (AP). Après l'induction de l'anesthésie chez 30 patientes, un tube muni d'une électrode superficielle a été placé dans la trachée avant l'administration d'agent myorelaxant pour permettre le monitorage électromyographique (EMG) des muscles adducteurs du larynx. Le monitorage de la transmission neuromusculaire consistait à l'EMG des muscles adducteurs du larynx et de l'AP gauche. Les patientes ont été réparties aléatoirement en deux groupes. Après la stimulation transcutanée du nerf laryngé récurrent et des nerfs cubitals, un bolus de rocuronium de $0,6 \mathrm{mg} \cdot \mathrm{kg}^{-1}$ (groupe Bolus) ou une dose d'amorçage de $0,06 \mathrm{mg} \cdot \mathrm{kg}^{-1}$ de rocuronium suivis de $0,54 \mathrm{mg} \cdot \mathrm{kg}^{-1}$ de rocuronium trois minutes plus tard (groupe Amorçage) ont été injectés. La période latence, le moment où le bloc est installé à $90 \%$, le délai d'installation et le moment de l'effet maximal du BNM ont été notés et comparés ; un $P<0,05$ était considéré significatif.

Résultats : Le bloc neuromusculaire à $90 \%$ et le délai d'installation mesurés aux adducteurs du larynx (début: 44,7 \pm 7,4 vs 74,0 \pm 23,8 sec) et à l'AP (début: 105,4 \pm 29,9 vs 139,2 \pm 1 I,5 sec) ont été significativement plus courts dans le groupe Amorçage que dans le groupe Bolus. À l'intérieur des groupes, les délais d'installation du bloc ont été significativement plus courts aux muscles laryngés qu'à l'AP.

Conclusion : Une technique d'amorçage avec du rocuronium accélère de façon significative l'installation du BNM aux muscles adducteurs du larynx. De plus, nos résultats sont en faveur de l'usage de rocuronium pour remplacer la succinylcholine dans l'induction en séquence rapide.

From the Departments of Anesthesiology, University of Erlangen-Nuremberg, ${ }^{*}$ Erlangen, Germany; and the Centre Hospitalier de l’Université de Montréal, $†$ Montreal, Quebec, Canada.

Address correspondence to: Dr. Joachim Schmidt, Department of Anesthesiology, University of Erlangen-Nuremberg, Krankenhausstr.

12, D-91054 Erlangen, Germany. Phone: $\pm 49-9131-8533680$; Fax.: $\pm 49-9131-8536147$; E-mail: joachim.schmidt@gmx.ch

Accepted for publication April 16, 2004.

Revision accepted September 10, 2004. 


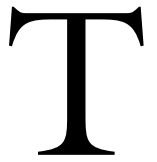

HE standard anesthetic technique used for patients considered to be at risk of aspiration is known as rapid sequence induction (RSI). In order to prevent aspiration, the time between induction of anesthesia and intubation of the trachea should be kept as short as possible. Neuromuscular blocking agents are given as part of the RSI to facilitate a safe and rapid tracheal intubation. Succinylcholine is still the most frequently used neuromuscular blocking agent for RSI because of its fast onset and fast recovery, despite known side effects. ${ }^{1}$ Several techniques like timing, mega-dose or priming can possibly shorten the onset time of nondepolarizing neuromuscular blocking agents. While timing is potentially unpleasant and dangerous for the patient, the bolus injection of a mega dose has not consistently achieved the rapid onset time of succinylcholine and prolongs the duration of action of neuromuscular blocking agents.

Rocuronium is a neuromuscular blocking agent with a fast onset and intermediate duration. The onset time of rocuronium is significantly shorter than equivalent doses of any other non-depolarizing neuromuscular blocking agent. ${ }^{2}$ Rocuronium $0.9 \mathrm{mg} \cdot \mathrm{kg}^{-1}(3 \times$ $\mathrm{ED}_{95}$ ) was recommended as an alternative to succinylcholine for RSI in patients with contraindications to succinylcholine. ${ }^{1}$ However, in comparison to rocuronium $0.6 \mathrm{mg} \cdot \mathrm{kg}^{-1}$, the recovery of neuromuscular transmission to $90 \%$ of control twitch height is increased from $45 \mathrm{~min}$ to $75 \mathrm{~min}$ at the adductor pollicis muscle $(\mathrm{AP}) .^{3}$

The priming principle allows to shorten the onset time of a non-depolarizing neuromuscular blocking agent without increasing the duration of action by the application of a small dose two to six minutes prior to the larger intubation dose. ${ }^{4,5} \mathrm{~A}$ small dose of a nondepolarizing neuromuscular blocking drug should not cause unpleasant symptoms, but the priming dose should occupy a considerable portion of the postsynaptic nicotinic acetylcholine receptors and shorten the onset time after administration of the intubation dose. Priming with rocuronium has been shown to shorten onset of neuromuscular blockade (NMB) at the AP. ${ }^{6-9}$ The laryngeal muscles are important because they play a pivotal role in airway maintenance and protection. We know that the time course and potency of muscle relaxants differ at the laryngeal muscles as compared with the AP. ${ }^{10}$ However, the effects of priming on laryngeal adductor muscles have not been studied objectively.

We compared a bolus administration of rocuronium $0.6 \mathrm{mg} \cdot \mathrm{kg}^{-1}$ vs a priming technique consisting of rocuronium $0.06 \mathrm{mg} \cdot \mathrm{kg}^{-1}$ three minutes before rocuronium $0.54 \mathrm{mg} \cdot \mathrm{kg}^{-1}$ on the onset of $\mathrm{NMB}$ at the laryngeal adductor muscles and the AP.

\section{Methods}

After approval of the local Ethics Committee and written informed consent, 30 female patients scheduled for elective thyroid surgery were randomly assigned to the Bolus or the Priming group (15 patients each group) via random number draws. The anesthesiologist recording pharmacodynamic data was blinded to group assignment.

Patients who were pregnant or who had significant neuromuscular, renal, hepatic, cardiovascular or respiratory diseases, cardiac arrhythmias, pacemakers, chemotherapy or patients receiving drugs known or suspected to interact with neuromuscular blocking agents were excluded. Other exclusion criteria were a body mass index $>27$, gastroesophageal reflux and an abnormal upper airway.

A standardized anesthetic technique was used in both groups. Routine monitoring consisted of an electrocardiogram, non-invasive blood pressure and pulse oximetry. Body temperature was measured by an esophageal thermistor and maintained at $36.5 \pm 0.5^{\circ} \mathrm{C}$ with a heating blanket (Bair Hugger ${ }^{\circledR}$, Augustine, Eden Prairie, MN, USA). Skin temperature was recorded at the left forearm.

After preoxygenation for at least three minutes, anesthesia was induced with remifentanil 0.5 $\mu \mathrm{g} \cdot \mathrm{kg}^{-1} \cdot \mathrm{min}^{-1}$. Two minutes later, a target controlled infusion (TCI) of propofol (target concentration: 4 $\mu \mathrm{g} \cdot \mathrm{mL}^{-1}$, programmed to reach the target within one minute) was started. After loss of consciousness, the lungs were ventilated with a face mask for two min-

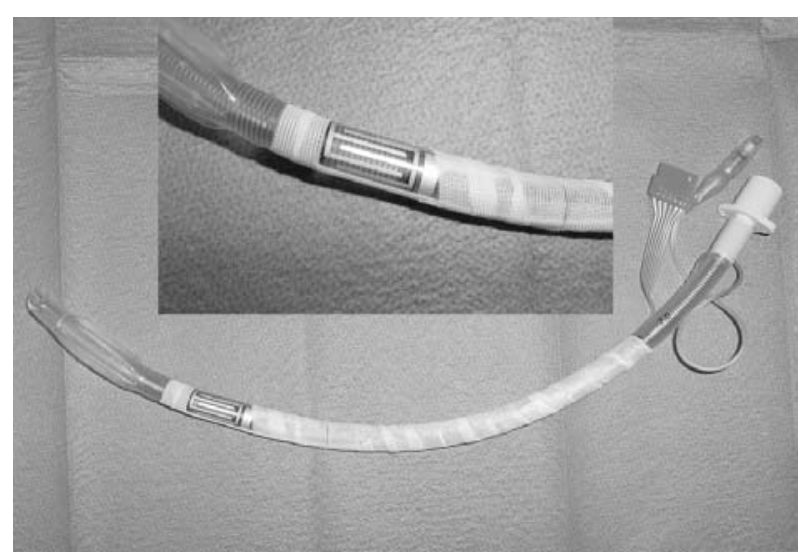

FIGURE 1 Endotracheal tube with laryngeal surface electrode attached $2 \mathrm{~cm}$ above the cuff; the enlarged surface electrode is shown in the small upper window. 
example of evoked laryngeal electromyography

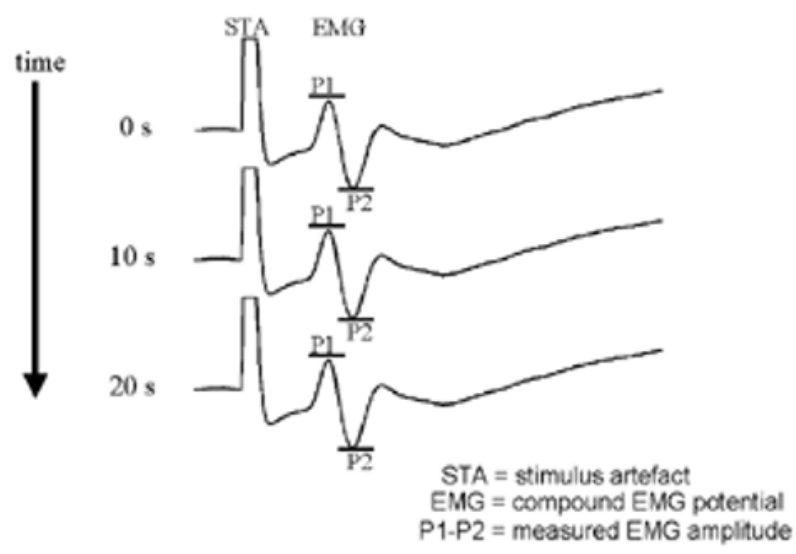

FIGURE 2 Example of evoked electromyography of the laryngeal adductor muscles. Timeframe, stimulus artefact (STA) and points $(\mathrm{P} 1, \mathrm{P} 2)$ of peak to peak measurements are indicated. Amplitude height P1-P2 was measured as the neuromuscular response of the laryngeal muscles. evoked laryngeal electromyography after priming

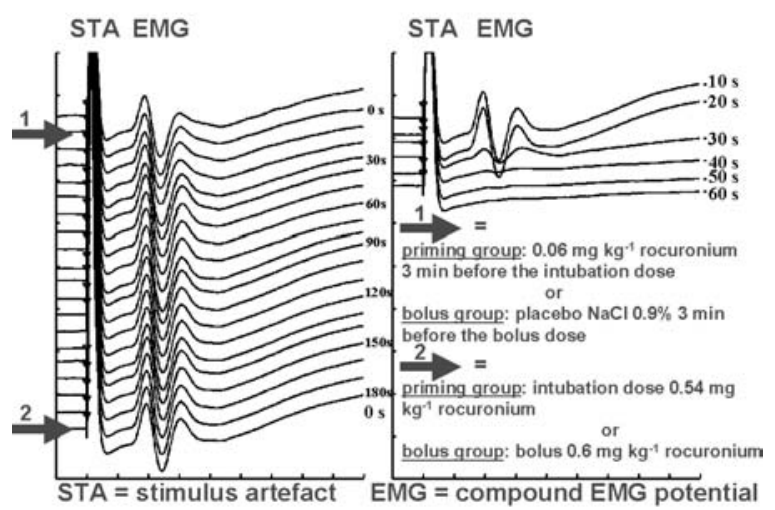

FIGURE 3 Evoked electromyography (EMG) of the laryngeal adductor muscles after priming for a representative patient. During the priming interval ( $180 \mathrm{sec}$, between arrows 1 and 2 ) no significant change in the amplitude of the evoked larynx EMG was found (left panel); after the intubation dose (arrow 2) the onset of neuromuscular block was accelerated (right panel, following the end of left panel).

transcutaneous supramaximal stimulation of the recurrent laryngeal nerve $(0.1 \mathrm{~Hz}, 35-60 \mathrm{~mA})$ and the ulnar nerve $(0.1 \mathrm{~Hz}$, single twitch, 50-65 mA), a placebo infusion ( $10 \mathrm{~mL} \mathrm{NaCl} 0.9 \%$ over five seconds) followed by a bolus of rocuronium $0.6 \mathrm{mg} \cdot \mathrm{kg}^{-1}$ three minutes later were administered in the Bolus group. The Priming group received a priming dose of rocuronium $0.06 \mathrm{mg} \cdot \mathrm{kg}^{-1}$ (diluted in $\mathrm{NaCl} 0.9 \%$ to a volume of $10 \mathrm{~mL}$ over five seconds) followed by rocuronium $0.54 \mathrm{mg} \cdot \mathrm{kg}^{-1}$ three minutes later injected over five seconds via a fast flowing Ringer's solution.

Time from injection of intubation dose to first depression of $\mathrm{Tl}$ (lag time), time to $90 \%$ depression of $\mathrm{Tl}$ (onset 90\%), time to maximum block (onset time) and the maximum $\mathrm{Tl}$ depression (peak effect) were recorded at the laryngeal adductor muscles using Multiliner ${ }^{\circledR}$ software and at the AP using the Datex Relaxograph ${ }^{\circledR}$ according to Good Clinical Research practice criteria of the Copenhagen Consensus Conference. ${ }^{11}$ In order to prevent a delay in the surgical procedure we did not measure the duration of $\mathrm{NMB}$ at the laryngeal muscles.

Sample size was calculated to achieve a power of 0.9 for an anticipated reduction of onset time of $25 \%$ in the Priming group with a mean expected onset time of $90 \mathrm{sec}$ and standard deviation of $30 \mathrm{sec}$ in the Bolus group. Demographic and pharmacodynamic data

After establishing stable recording conditions of neuromuscular transmission for at least ten minutes of 
TABLE I Patient characteristics

\begin{tabular}{lll}
\hline & Bolus group & Priming group \\
\hline Patients $(n)$ & 15 & 15 \\
Age $(\mathrm{yr})$ & $48.2 \pm 14.7$ & $50.1 \pm 18.2$ \\
Weight $(\mathrm{kg})$ & $65.3 \pm 9.7$ & $67.1 \pm 8.7$ \\
Height $(\mathrm{cm})$ & $165.0 \pm 5.2$ & $163.5 \pm 4.0$ \\
Body mass index & $24.1 \pm 3.2$ & $25.1 \pm 3.0$ \\
ASA physical status I/II/III & $6 / 8 / 1$ & $8 / 6 / 1$ \\
\hline
\end{tabular}

TABLE II

\begin{tabular}{lll}
\hline & Bolus group & Priming group \\
\hline Laryngeal adductor muscles & & \\
Lag time (sec) & $28.6 \pm 11.2$ & $24.6 \pm 9.2$ \\
Onset 90\% (sec) & $67.9 \pm 24.4 \#$ & $41.1 \pm 7.1^{*} \#$ \\
Onset (sec) & $74.0 \pm 23.8 \#$ & $44.7 \pm 7.4^{*} \#$ \\
Peak effect \% & $93 \pm 11$ & $94 \pm 9$ \\
Adductor pollicis muscles & & \\
Lag time (sec) & $24.6 \pm 12.7$ & $23.9 \pm 10.4$ \\
Onset 90\% (sec) & $115.8 \pm 40$ & $88.5 \pm 21.1^{*}$ \\
Onset (sec) & $139.2 \pm 51.5$ & $105.4 \pm 29.9^{*}$ \\
Peak effect \% & $94 \pm 9$ & $95 \pm 9$ \\
\hline
\end{tabular}

${ }^{*} P<0.05$ between the bolus group and the priming group for the same monitoring site. $\# P<0.05$ within the groups between the different monitoring sites (laryngeal adductor muscles $v s$ adductor pollicis muscles).

between the two groups were compared using the Mann-Whitney U test; the Wilcoxon-test was used to determine a significant difference between the different muscles within groups. Results are shown as mean $\pm \mathrm{SD} ; P<0.05$ was considered statistically significant.

\section{Results}

Demographic data were similar with respect to age, height, weight, body mass index as well as ASA physical status (Table I). The onset $90 \%$ and onset time at the laryngeal adductor muscles and the AP were significantly shorter in the Priming group. However, lag time and peak effect were not different between the two groups (Table II).

Within the Bolus and Priming groups the onset $90 \%$ and the onset time were significantly shorter at the laryngeal adductor muscles in comparison to the AP (Table II). During the priming interval we did not find any significant change in the amplitude of evoked larynx electromyography in the Priming or the Bolus group.

\section{Discussion}

The administration of a priming dose of rocuronium $0.06 \mathrm{mg} \cdot \mathrm{kg}^{-1}$ followed three minutes later by an intu- bation dose of rocuronium $0.54 \mathrm{mg} \cdot \mathrm{kg}^{-1}$ accelerates the onset of $\mathrm{NMB}$ at both the laryngeal adductor muscles and the AP in comparison to the bolus administration of rocuronium $0.6 \mathrm{mg} \cdot \mathrm{kg}^{-1}$.

In this study, offset of NMB was not studied in order to avoid delaying surgery. The important impact of priming is the diminution of onset time, especially in situations where rapid establishment of a secure airway is mandatory such as in RSI. However, there are several studies which have shown that priming does not prolong the clinical duration of NMB in comparison to a non-priming technique. . $^{8,9,12}$

We deliberately chose a priming interval of three minutes since the size of the priming and intubation dose as well as the priming interval are important for the effect of the priming technique. Yavascaoglu et al. ${ }^{13}$ studied different priming intervals (two and three minutes) and priming dosages (priming dose: rocuronium 0.06 or $0.1 \mathrm{mg} \cdot \mathrm{kg}^{-1}$, intubation dose 0.54 or $\left.0.5 \mathrm{mg} \cdot \mathrm{kg}^{-1}\right)$. They found that priming with a threeminute interval shortened the onset time of rocuronium irrespectively of the dosage, while a two-minute priming interval did not significantly decrease the onset time. Naguib et al. ${ }^{9}$ could also demonstrate that priming three minutes prior to an intubation dose significantly shortened the onset time at the AP.

Whereas for most neuromuscular blocking drugs, onset of NMB is faster at the larynx than at the AP, results for rocuronium are still controversial. Meistelman et al. ${ }^{14}$ observed a significantly shorter onset time at the larynx $(1.4 \pm 0.1 \mathrm{~min})$ than at the AP $(2.4 \pm 0.2 \mathrm{~min})$ after administration of rocuronium $0.5 \mathrm{mg} \cdot \mathrm{kg}^{-1}$. Wright et al..$^{15}$ found a shorter onset time at the larynx $(92 \pm 29 \mathrm{sec})$ vs the $\operatorname{AP}(155 \pm 40 \mathrm{sec})$ after application of rocuronium $0.4 \mathrm{mg} \cdot \mathrm{kg}^{-1}$ but similar onset times after rocuronium 0.8 and $1.2 \mathrm{mg} \cdot \mathrm{kg}^{-1}$. In both studies neuromuscular transmission was monitored by the cuff pressure method at the larynx and mechanomyography at the AP. In another study, the onset times did not differ between the larynx (124 \pm $39 \mathrm{sec})$ and the AP $(115 \pm 21 \mathrm{sec})$ as measured by EMG after a bolus of rocuronium $0.6 \mathrm{mg} \cdot \mathrm{kg}^{-1} .{ }^{16}$ Hemmerling et al. ${ }^{3}$ described significant differences in the onset times at the larynx $(106 \pm 38 \mathrm{sec}, 64 \pm 30$ $\mathrm{sec})$ and the $\mathrm{AP}(145 \pm 48,99 \pm 31 \mathrm{sec})$ after bolus doses of rocuronium 0.6 and $0.9 \mathrm{mg} \cdot \mathrm{kg}^{-1}$, respectively. These results are in agreement with those of our current study. The reasons for these discrepancies are probably dose-related, doses smaller than $2 \times \mathrm{ED}_{95}$ producing a faster onset, but a less pronounced peak effect at the larynx in comparison to the AP; in addition, the method of neuromuscular monitoring at the AP might have influenced the results in these studies. 
The clinical impact of our study relates to the use of neuromuscular blocking drugs for RSI. Since the onset time of NMB at the laryngeal adductor muscles after our priming technique is similar to the onset time following $1 \mathrm{mg} \cdot \mathrm{kg}^{-1}$ succinylcholine and even faster than a bolus of rocuronium $0.9 \mathrm{mg} \cdot \mathrm{kg}^{-1},{ }^{3}$ anesthesiologists who want to avoid succinylcholine because of its side effects and rocuronium $0.9 \mathrm{mg} \cdot \mathrm{kg}^{-1}$ because of its long duration of action, should use the priming technique presented here.

Optimal priming should hasten the onset of neuromuscular block without producing any side effects. A priming dose of $10 \%$ of the standard intubation dose and a priming interval of three to four minutes have been recommended as safe and effective. ${ }^{8}$ Kopman and colleagues ${ }^{12}$ concluded, in their theoretical analysis of safety and timing, that in one of 50 patients the recommended priming dose of $0.06 \mathrm{mg} \cdot \mathrm{kg}^{-1}$ might produce a measurable neuromuscular depression. Even if we did not find a significant change in the amplitude of the evoked larynx EMG during the priming interval, priming may cause side effects like hypoventilation, reduced lung volumes and regurgitation and may jeopardize patient safety. ${ }^{17}$ Especially in obese, old or somnolent patients the benefits and risks of a priming technique should be evaluated carefully.

In conclusion, priming with rocuronium accelerates the onset of NMB at the laryngeal muscles and at the AP. This technique can be helpful if tracheal intubation has to be achieved quickly without the use of succinylcholine or if a prolonged duration of action by the application of a mega dose of rocuronium is not desired. However, priming should be performed cautiously and the patient monitored closely.

\section{References}

1 Sparr HJ. Choice of the muscle relaxant for rapidsequence induction. Eur J Anaesthesiol 2001; 18(Suppl. 23): 71-6.

2 Wierda JM, Hommes FD, Nap HJ, van den Broek L. Time course of action and intubating conditions following vecuronium, rocuronium and mivacurium. Anaesthesia 1995; 50: 393-6.

3 Hemmerling TM, Schmidt J, Wolf T, Klein P, Jacobi K. Comparison of succinylcholine with two doses of rocuronium using a new method of monitoring neuromuscular block at the laryngeal muscles by surface laryngeal electromyography. Br J Anaesth 2000; 85: 251-5.

4 Hofmockel R, Benad G, Kabott A. Mechanomyographic and electromyographic studies of endotracheal intubation with 2 different rocuronium dosages. Anaesthesiol Reanim 1994; 19: 144-8.
5 Foldes FF, Nagashima H, Kornak PH. Effect of priming. Anaesth Pharmacol Rev 1993; 1: 49-56.

6 Foldes F. Rapid tracheal intubation with non-depolarizing neuromuscular blocking drugs: the priming principle (Letter). Br J Anaesth 1984; 56: 663.

7 MiIIer RD. The priming principle (Editorial). Anesthesiology 1985; 62: 381-2.

8 Griffith KE, Joshi GP, Whitman PF, Garg SA. Priming with rocuronium accelerates the onset of neuromuscular blockade. J Clin Anesth 1997; 9: 204-7.

9 Naguib $M$. Different priming techniques, including mivacurium, accelerate the onset of rocuronium. Can J Anaesth 1994; 41: 902-7.

10 Hemmerling TM, Donati F. Neuromuscular blockade at the larynx, the diaphragm and the corrugator supercilii muscle: a review. Can J Anesth 2003; 50: 779-94.

11 Viby-Mogensen J, Engbaek J, Eriksson LI, et al. Good clinical research practice (GCRP) in pharmacodynamic studies of neuromuscular blocking agents. Acta Anaesthesiol Scand 1996; 40: 59-74.

12 Kopman AF, Khan NA, Neuman GG. Precurarization and priming: a theoretical analysis of safety and timing. Anesth Analg 2001; 93: 1253-6.

13 Yavascaoglu B, Cebelli V, Kelebek N, Uckunkaya N, Kutlay O. Comparison of different priming techniques on the onset time and intubating conditions of rocuronium. Eur J Anaesthesiol 2002; 19: 517-21.

14 Meistelman C, Plaud B, Donati F. Rocuronium (ORG 9426) neuromuscular blockade at the adductor muscles of the larynx and adductor pollicis in humans. Can J Anaesth 1992; 39: 665-9.

15 Wright PM, Caldwell JE, Miller RD. Onset and duration of rocuronium and succinylcholine at the adductor pollicis and laryngeal adductor muscles in anesthetized humans. Anesthesiology 1994; 81: 1110-5.

16 Dhonneur G, Kirov K, Slavov V, Duvaldestin P. Effects of an intubating dose of succinylcholine and rocuronium on the larynx and diaphragm. Anesthesiology 1999; 90: 951-5.

17 Aziz L, Jahangir SM, Choudhury SN, Rahman K, Obta $\Upsilon$, Hirakawa $M$. The effect of priming with vecuronium and rocuronium on young and elderly patients. Anesth Analg 1997; 85: 663-6. 